\title{
Development of African Materials Research and Education for the 21st Century
}

\section{Abebe Kebede and Alfred Z. Msezane}

Africa is a paradox which illustrates and highlights neo-colonialism.

Her earth is rich, yet the products that come from above and below the soil continue to enrich, not Africans predominantly, but groups and individuals who operate to Africa's impoverishment.

—Kwame Nkrumah (1900-1972),

Ghanaian president. Neo-Colonialism (1965), chap. 1

\section{Introduction}

Africa accounts for $11-45 \%$ of the world supply of eight major mineral commodities as well as $13 \%$ of the world's bauxite, the principal source of aluminum. It possesses a tremendous capacity in agriculture, and it has a diverse variety of plants and animals. Of the 356 biosphere reserves, 48 are in Africa. ${ }^{1}$ Despite such riches, the per capita income of Africans is much lower than those in industrialized nations. The goals of materials research and education in the 21st century should not be to uncover new and exotic materials, but primarily to address the critical needs of the populations of Africa. The development of water resources, building materials for housing, textiles, efficient food production, and health care must take center stage. The African mineral industry is export-oriented; thus the economy is exposed to world market fluctuations. ${ }^{1}$ Materials research in the 21st century should also focus on diversifying Africa's mineral industry to open new industries that turn raw material into commodities.

In this brief article, we will discuss the current state of higher education, the conditions that hinder scientific research, and the possible development direction for materials research and education in Africa for the 21st century. Materials science is an interdisciplinary field of study that focuses on the structure, properties, and application of various kinds of materials. These aspects are studied using the principles of chemistry and physics to develop new materials and modify existing ones for applications that enhance the quality of life. The majority of Africans have not benefited from the advent of materials science in comparison with the populations of the west and the north. It is beyond the scope of this article to provide an analysis of the complex political, economic, and social conditions that led to such a contrast.

Africa has over 350 higher education institutions with a variety of experiences and priorities. The primary objective of these institutions is to produce white-collar workers, teachers, and the work force for mining, textiles, and agricultural industries. The state of higher education and scientific research in Africa has been discussed in several conferences. The proposals that are generated by these conferences advocate structural changes in higher education, North-South institutional linkages, mobilization of the African Diaspora, funding, and so on. As a consequence of these declarations, many African institutions are developing education and research programs that will lead to the development of human resources, faculty, $\mathrm{PhD}$ programs, and infrastructure. One example of mobilization of the African Diaspora is the establishment of the Edward Bouchet/Abdus Salam Institute by Professor Abdus Salam, in October 1988, with the purpose of facilitating and enhancing scientific partnerships between African and U.S. scientists. Funding is also becoming available through international organizations and donor governments. Recently, three major U.S.-based foundations pledged funding for the purpose of developing higher education programs in Africa.

Despite these efforts, the higher education programs in many African countries are not near their Western counterparts in vital areas such as productivity, quality of education, and research. A recent World Bank document ${ }^{2}$ labels institutions situated in Sub Saharan Africa (SSA) as ineffective to address the needs of their populations and to maintain viable education and research programs. The institutions suffer from inadequate infrastructure, absence of faculty development opportunities, and inadequate funding. More importantly, it is difficult for these institutions to attract high caliber postdoctorates and junior and senior faculty members to join their materials programs because the institutions cannot provide the same competitive opportunities as institutions in the United States and Europe. The overall effect of these conditions leads to the flight but also the defection of highly skilled Africans from Africa. This, in turn, widens the knowledge gap between Africa and the industrialized continents and degrades the quality of African graduates in science, mathematics, engineering, and technology (SMET).

A recent article by James Lamout (Financial Times, August 2, 2001) indicates that emigration from South Africa alone costs $\$ 8.9$ billion in lost human resources. The article also stated that every year 23,000 graduates leave Africa for opportunities overseas, mainly in Europe, leaving only 20,000 scientists and engineers serving over 600 million people. The International Organization for Migration states that the brain drain of highly skilled professionals from Africa is making economic growth and poverty alleviation impossible across the continent.

The scientific progress of Africa in the 21st century depends on how effectively we address the higher education infrastructure and human resources in research and development (R\&D). Enrollment in technical fields and natural and applied sciences must increase. The Africa Development Report ${ }^{3}$ and Human Development Report ${ }^{4}$ indicate only $6.7 \% 5$ of the students who were in secondary schools in 1988-1991 enrolled in natural and applied fields. In 1992, $26.7 \%$ of the total tertiary students were enrolled in the same fields. ${ }^{6}$ From 1985 to 1992, the percentage of tertiary students abroad compared to those at home was $18.5 \%{ }^{7}$ According to a survey of 10 SSA countries during 1988-1992, the count of R\&D scientists and technicians was 0.45 per 1000 people. The average over 10 countries (including South Africa) shows that the R\&D investment as a percent of the GDP is 0.4 . The manufacturing value added (MVA) as \% GDP in 1994 was $11.6 \%$ averaged over for 28 countries in SSA. The key here is to increase enrollment in natural and applied science at the secondary and tertiary level, utilize the African expertise abroad, and increase R\&D human resources for MVA.

Materials science education and research can become instrumental in creating niches in the manufacturing sector to enhance the MVA. Enormous funding must be made available to remodel higher education programs after their western counterparts, where the expectations of society, government, and industries are truly integrated with the functions of the institutions. Most of all, the R\&D investment must increase. We are led to believe that such integration can be realized. Recent developments toward regional 
and continent-wide economic and cultural cooperation include the establishment of the African Union. The African scientific community and colleagues around the world can use this opportunity to lobby the new union for the establishment of the African Science Foundation that supports SMET education and research. Working groups and electronic discussion groups should be established in a variety of disciplines to chart the way for effective participation. The concept proposals for the African-Materials Research Society (Africa-MRS), the African Physics Forum, and the MRSAfrica ${ }^{8}$ Working Group, which we are developing, can be used as staging posts to generate materials education and research areas that impact sustainable development. There are over 500 scientists in the three groups.

\section{Textile, Wood, and Jewelry}

In addressing critical needs in Africa, some of the most attractive areas include textile, wood, and jewelry. The west and the north are developing the taste for African traditional garment, ornament, musical instruments, and metal works. One can easily find exotic African products such as the Ghanaian Kente, the Ethiopian Shema and crosses, the drums from Benin, and the fertility symbol from Nigeria, for example. In addition, the significance and development of cultural traditions such as Kwanzaa in the United States contributes to the large market for African textiles, wood, and jewelry. Materials research and education in the 21st century should focus on the science and technology of fiber and textile, wood, and jewelry.

\section{Materials for Building, Agriculture, and the Environment}

Much of Africa's population live in adobe-walled, straw-roofed houses in the rural areas and in shanty houses in the urban areas. There is a dire need for the development of affordable and environmentally friendly materials for energyefficient housing. There will be an extensive use of advanced composite materials based on local resources including forestry, agriculture, natural fibers, plant materials, and agricultural and industrial wastes. ${ }^{8}$ Materials science in the 21st century must impact the agriculture sector in the development of new, strong, and safe farming tools; food production; mechanization of produce transport; solar/wind energybased grinding machines, and stoves and cookware. In addition, the advent of transgenic science may provide opportunities for the development of bio-metals such as bio-steel. Materials science can also be instrumental in the development and preservation of medicinal plants. Furthermore, the materials science focus on the environment will play a crucial role in the preservation of the African ecosystems by developing materials appropriate for the global environment. In this respect, education and research programs can be developed to understand the science of the environment and factors that are detrimental to global change.

\section{Time Line \\ The First 10 Years}

The population of Africa is expected to rise to 1.2 billion in the next 20 years. The key elements for materials science should be in place to tackle the problems that may arise due to such a population explosion. What we can do is develop U.S.-Africa working groups in all science disciplines that propose research and education areas, and advise and enhance collaborations with African institutions. The U.S.-Africa materials science linkage can be developed through an annual U.S.-Africa materials conference. The conference would establish common research priorities, models of collaborations, and a base line for the level of support and involvement of U.S. scientists and institutions. Within the existing global alliances for education, the emerging African scientific and academic societies will provide a fertile ground for collaboration. The working groups will also devise development strategies for High Caliber Undergraduate and Graduate Education in materials science at both secondary and tertiary level schools.

\section{The First 100 Years}

During the first 20 years, Centers of Excellence and Institutes should be established in countries where there is adequate human and physical resources. Such large-scale endeavors would require tremendous commitment from African governments, the private sector, and higher education administrators. These centers and institutes would have similar features to multi-university research centers or national laboratories in the United States. The host countries could be chosen to represent the linguistic and geographical characteristics of the continent. For example, Ghana could serve the English-speaking west; Senegal, the French-speaking countries; Tanzania in the East; and South Africa in the South. The next 20 years should witness the establishment of the African-Materials Research Society and African Science Foundation, which would be supported and managed by the African Union and the private sector. By 30 years from now, homegrown basic research should flourish in every African country and productivity should increase tenfold. There would be fully operational materials research societies and well-developed national science foundations. By 40 years, materials science in Africa should reach such a level that a large number of $R \& D$ and mainstream companies would expand in Africa. Members of the materials research societies would become comparable to the current MRS. By the end of this century, then, the economy of most of the African countries will take over the current developing countries.

\section{Conclusions}

In a recent U.S.-Africa materials workshop sponsored by the National Science Foundation and the National Research Foundation of South Africa, several faculty members from a good portion of Africa gathered to discuss issues pertaining to materials education and research in the continent. The participants identified, as an organizational priority, the establishment of the African-Materials Research Society (African-MRS) with mandates similar to MRS. With the establishment of African-MRS, we believe that educators in the region will chart the direction of materials research and education, and the development of a high-end applicable materials program in Africa. South Africa, as a consequence of its history, possesses materials research and education activity comparable with that in the United States. It is difficult at this time to assess materials programs in the rest of the African countries. However, we expect that Egypt, Tunisia, and Algeria in the North; Nigeria, Ghana, Senegal, and Cameroon in the West; Tanzania, Kenya, and Ethiopia in the East; and Zimbabwe, Botswana, Mauritius, and Seychelles in the South may have modest programs.

We would like to conclude by saying that the key to a successful materials science program begins by enabling African universities to do basic and applied research in SMET. This involves faculty development and exchange programs, curriculum design and enhancement, the availability of adequate infrastructure, and literature resources. Advanced researchbased laboratories must be introduced into the undergraduate SMET curriculum. The laboratories can be designed in collaboration with local industries, hospitals, and research institutions. We must exploit the opportunities offered by information technologies to develop distance education programs and data exchange mechanisms to strengthen the educational programs. In 
this regard, the development and adaptation of information technology in Africa must become an integral part of this endeavor. Finally, the progress of the west and the north are due to relative peace in the region. The recent turf wars in Liberia and Angola for diamond, and the TustsiHut conflict, which led to the massacre of several thousand civilians, constitute the dark moments of Africa. African leaders and intellectuals must take the path of peaceful coexistence for Africa to develop.

\section{References}

1. G.J. Coakley, B. Michalski, and P.M. Mobbs U.S. Geological Survey (Reston, VA, 1995).

2. E. Baranshamaje "The African Virtual University (AVU): Concept Paper" (World Bank, Washington, 1995).

3., "African Development Report" (African Development Bank, Abijan, Ivory Coast, 1994). 4. "Human Development Report" (United Nations Development Programme, New York, 1996).

5. This is the average over 34 countries in SSA 6. This is the average over 30 countries in SSA

7. This is the average over 36 countries in SSA 8. INDIA-UNIDO exhibition on building materials and manufacturing technologies for low-cost housing in AFRICA Exhibition: June 30-July 9, 2000, Saba Saba Grounds, Dar-esSalaam, Tanzania.

9. MRS-Africa Working Group was established during the 2000 MRS Fall Meeting in November.

Abebe Kebede is Associate Professor in the Department of Physics at North Carolina AET State University. He is a member of the American Physical Society, and a founding

\section{Suggested Reading:}

1. Africa Physics Forum (http://trigonal. ncat.edu/afps)

2. African Materials Research Society concept (http://trigonal.ncat.edu/)

3. U.S.-Africa Fundamental and Applied Sciences Conference (http://www. physics. ncat.edu/ michael/usafas)

4. U.S.-Africa Materials Workshop, August 2000, Pretoria South (http: //www.iumrs.org)

5. Financial Times Thursday August 2, 2001

6. International Conference on Optical

Sciences and Applications for Sustainable

Development (http:/ / www.ico-optics. org/dakar.html)

7. African Development Forum: (http: / / www.un.org / Depts / eca / adf / wk8sumen. htm)

8. APS: Workshop Explores Collaboration with Africa (http://www.aps.org/ apsnews/0498/041298.html)

9. World Conference on Science (http: //www.nature.com/wcs/1news/02-1c. html)

10. Third World Academy of Sciences (http://www.ictp.trieste.it/TWAS/)

11. UNESCO Physics Action Council (http://www.aps.org/intaff/work.html) member of the Materials Research SocietyAfrica Working Group. He is also a founding member of the Ethiopian Distance Learning Association and the African Distance Learning Association. He is instrumental in establishing several Africa Education Networks including the African-Materials Research Society and the Africa Physics Forum. These networks serve over 500 scientists throughout Africa. Kebede received his BS degree in physics in 1982 from Addis Ababa University, Ethiopia; and his MA (1986) and PhD (1990) degrees in physics from Temple University, Philadelphia. His research is in the area of condensed-matter physics.

Alfred Z. Msezane is a professor of physics and the director of the Center for Theoretical Studies of Physical Systems (CTSPS) at Clark Atlanta University (CAU) in Georgia. He has received the BSc and $B S c$ (Hons) degrees from the University of South Africa in 1962 and 1964, respectively, and the MSc and $P h D$ degrees in physics from the University of
Saskatchewan (1968) and the University of Western Ontario (1973), respectively. Msezane has previously worked at Witwatersrand University (South Africa, 1968-1969), Georgia State University (1974-1976), University of New Brunswick (1976-1978), Louisiana State University (1978-1980), Morehouse College (1980-1083), and Atlanta University (19831989). He has carried out research at ITAMP of Harvard University and consulted at Lawrence Livermore National Laboratory. Msezane's current research projects include electron/ photon interactions, particularly nondipole effects in atoms, and the elucidation of smallangle electron scattering through innovative theoretical approaches. His honors include the Edward A. Bouchet Award presented by the American Physical Society (APS) (1999), APS Fellow (1999), and the DSc (Honoris Causa) degree from Fort Hare University (South Africa, 1998).
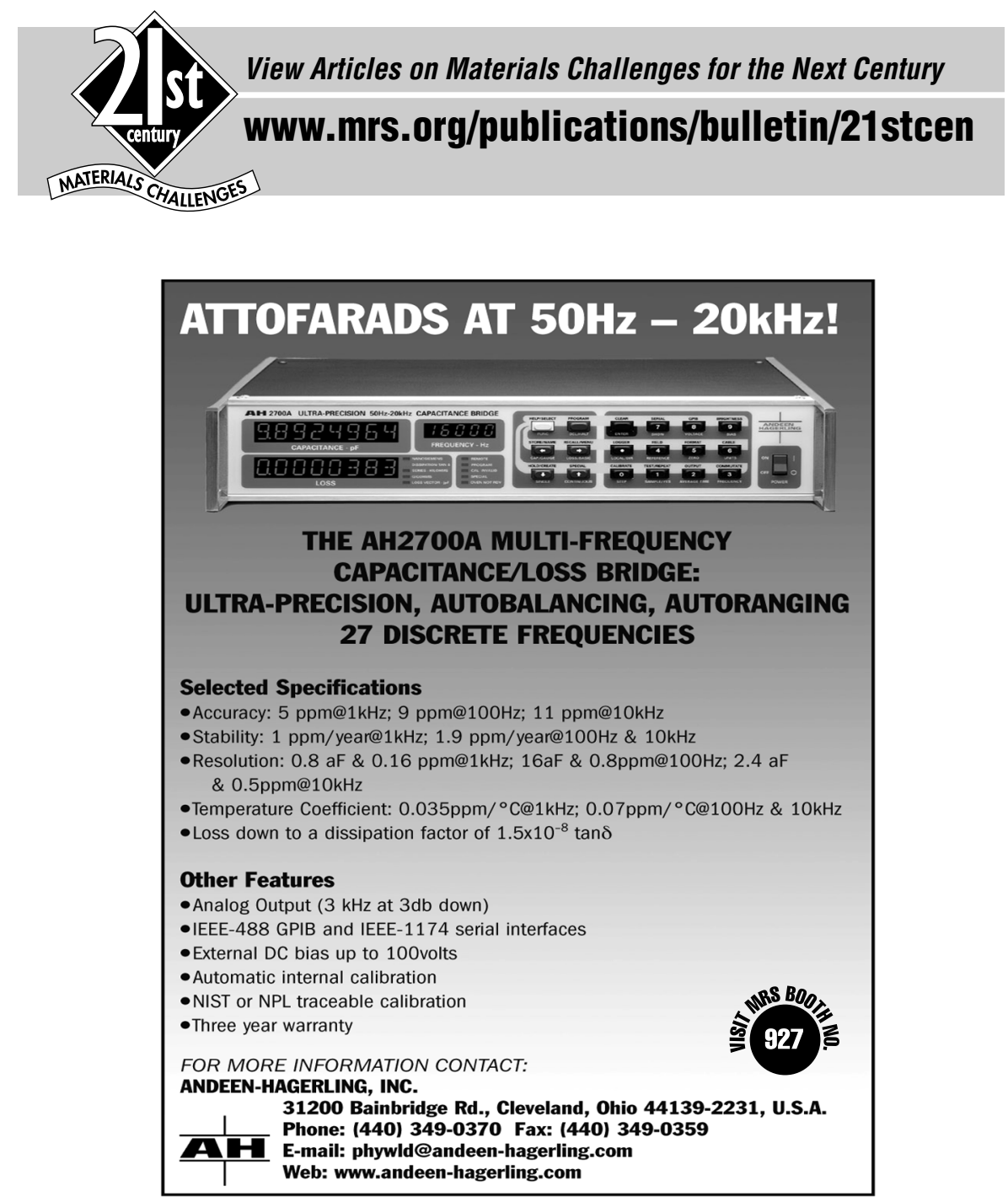

Circle No. 10 on Inside Back Cover 